\title{
SITIO EL PLOMO Y NUEVOS REGISTROS DE CULTÍGENOS INICIALES EN CAZADORES DEL ARCAICO IV EN ALTO MAIPO, CHILE CENTRAL
}

\author{
NEW EVIDENCE ON THE USE OF INITIAL CULTIGENS BY THE HUNTER- \\ GATHERER GROUPS OF THE ARCHAIC IV PERIOD AT EL PLOMO, \\ ALTO MAIPO, CENTRAL CHILE
}

María Teresa Planella ${ }^{1}$ Rosa Scherson ${ }^{2}$ y Virginia McRostie ${ }^{3}$

\begin{abstract}
Nuevas investigaciones arqueológicas en la cordillera andina de Chile central demuestran que cazadores recolectores del periodo Arcaico IV incorporaron el conocimiento y uso de cultígenos iniciales a su sistema de subsistencia. En el sitio El Plomo (3.460 a 3.340 años cal. a.p.) localizado a 2.070 metros de altitud, se reitera el hallazgo de frutos de Chenopodium (cf. Chenopodium quinoa) carbonizados además de otros Chenopodium en estado desecado que también presentan rasgos de domesticación. Los estudios morfológicos efectuados en estos últimos con el apoyo de especialistas sugieren que sus tamaños, entre 0,8 a $1 \mathrm{~mm}$ de diámetro, muestran similitudes con Chenopodium pallidicaule o cañihua, o corresponderían a una variedad temprana de quinoa. La ausencia de testa, entre otras características diagnósticas en estos frutos, hace difícil determinar su identidad con suficiente certeza. Esta problemática abre una nueva línea de discusión acerca de la domesticación de Chenopodium en Chile central. Se plantea además el aprovechamiento de otros recursos vegetales, que no han sido particularmente considerados como alimentos en el registro arqueológico de ocupaciones de cazadores recolectores tardíos en esta región. El sector de Alto Maipo en la cordillera de Chile central se propone como un umbral ecológico cultural donde ocurre tempranamente una importante innovación en el sistema básico de subsistencia de cazadores recolectores del período Arcaico.
\end{abstract}

Palabras claves: cazadores recolectores, Arcaico final, cultígenos iniciales, Chenopodium, alta cordillera, Chile central.

Recent archaeological research in the Andean highlands of Central Chile provides evidence that hunter-gatherers of the Archaic IV period incorporated knowledge and use of initial cultigens into their subsistence system. At the archaeological site of $\mathrm{El}$ Plomo (3,460-3,340 years cal BP), located at 2,070 m above sea level, charred and desiccated small fruits of Chenopodium (cf. Chenopodium quinoa), ranging from 0,8 to $1 \mathrm{~mm}$ in diameter, have been documented. Morphological analyses performed on the desiccated fruits suggest that their sizes parallel those of Chenopodium pallidicaule or cañihua, or correspond to an early variety of quinoa. The absence of testa or other diagnostic characteristics of these fruits makes any secure species identification difficult. This new finding opens a new line in the discussion of Chenopodium domestication in Central Chile. Additionally, we propose that other plant resources that had not been considered as foodstuffs by scholars in previous studies were used by the late huntergatherers in this region. The Alto Maipo location in Central Chile is suggested to have been an ecological and cultural threshold where hunter-gatherers of the Archaic IV period introduced a significant innovation into their basic subsistence system.

Key words: Hunter-gatherers, Late Archaic, initial cultigens, Chenopodium, Andean highlands Central Chile.

El periodo Arcaico integra en su largo desarrollo diversas situaciones culturales de búsqueda, experimentación y adaptación que gradualmente serán definitorias en los cambios en el modo de subsistencia que presentarán las comunidades cazadoras recolectoras cerca del 1.500 a.C. en la región central de Chile. La alta movilidad que caracteriza a estas comunidades, desplazándose hacia distintos territorios tras los productos de caza, materias primas líticas para su instrumental y el aprovechamiento estacional de frutos silvestres, abrió umbrales y oportunidades de contacto con otros grupos, algunos de ellos probablemente conocedores de adelantos en la incorporación de nuevas alternativas en su base de alimentación. Es a fines del Arcaico o Arcaico IV (Cornejo et al. 1998), entre el 3.000 a 300 a.C., cuando se visualiza con mayor claridad una tendencia a variaciones en el patrón de subsistencia de los cazadores. Si bien el instrumental no se modifica sustancialmente

\footnotetext{
1 Sociedad Chilena de Arqueología. El Amancai 505 Las Condes, Santiago, Chile. mtplanella@ gmail.com

2 Instituto de Ecología y Biodiversidad, Universidad de Chile. Las Palmeras 3425, Santiago. Dirección actual: Facultad de Ciencias Forestales y Conservación de la Naturaleza. Universidad de Chile. Santa Rosa 11315, Santiago, Chile. rscherson@uchile.cl 3 Cerro La Paloma II, 10915, Lo Barnechea, Santiago, Chile. virginia.mcrostie@gmail.com
} 
(Cornejo y Sanhueza 2003), los restos de alimentos en los basurales y fogones indican que la recolección comienza a estar acompañada de la exploración de nuevos recursos, producto de una relación cualitativamente distinta con la naturaleza, la que finalmente puede concurrir a desarrollos iniciales, pausados y no siempre deliberados de intervención de algunas poblaciones de plantas (Zeder et al. 2006). Uno de los aspectos que involucra dicha intervención y que puede ser registrado por la arqueobotánica es la presencia de cambios morfológicos en distintos órganos de las plantas, derivados de la manipulación antrópica como ha sucedido inicialmente con Chenopodium en Chile central antes que con otros cultígenos (Planella y Tagle 2004). Este paso importante en la economía y sociedad se ha visto en cazadores recolectores de otras áreas de Sudamérica (Gil 1997-98; Hastorf 1999; Lavallèe 2000; Lema 2009; Pearsall 1989, 1999) y en esta región ha sido el preámbulo de la emergencia de nuevas tecnologías, con las Comunidades Alfareras Iniciales (Sanhueza y Falabella 1999-2000), e incorporación de otros cultígenos, como el maíz, porotos, zapallo, que se verán en el periodo siguiente, el Alfarero Temprano.

La zona altoandina del Maipo en la cordillera de Chile central, a la luz de las evidencias, se plantea como un umbral ecológico cultural dentro de la región, en el cual se inicia una importante variación en la relación hombre-plantas desarrollada por cazadores recolectores. Esto ha sido confirmado por estudios arqueobotánicos en los sitios Las Morrenas 1 (Planella et al. 2005) y El Plomo (Fondecyt 1060228). Los hallazgos de Chenopodiaceae con algunos rasgos diagnósticos de intervención humana han llevado a modificar el conocimiento acerca estas sociedades, valorizando procesos acaecidos a fines del Arcaico que hasta ahora no tenían registro y referentes en la región.

\section{Ubicación del Sitio y Descripción de su Entorno Vegetal}

El sitio El Plomo está localizado a $2.070 \mathrm{~m}$ de altitud en la cordillera de los Andes, en una planicie flanqueada por una zona de vegas, en un sector de confluencia de los ríos Maipo y Blanco (Figura 1). Corresponde a un asentamiento al aire libre, cuyos depósitos culturales en los estratos superiores corresponden al Arcaico IV y los inferiores al Arcaico III (5.900 a 5.610 años cal. a.p.).
La localidad está inserta dentro de la distribución geográfica que en términos vegetacionales ha sido clasificada como Estepa Alto-andina de la cordillera de Santiago (Gajardo 1994), con predominio de especies de carácter xerófito representativas como Chuquiraga oppositifolia D. Don, y Valenzuelia trinervis Bertero ("guindillo"), arbustos y hierbas pulvinadas o en cojín como las "llaretas", Azorella madreporica Clos y Laretia acaulis (Cav.) Gillies \& Hook; agrupaciones de Stipa lachnophylla Trin. que forman "coironales", la comunidad de Patosia clandestina (Phil.) Buchenau, o "coirón de vega", y Juncus balticus Willd. o "junquillo" que caracterizan los sectores de vegas.

Estas vegas se mantienen como consecuencia del derretimiento anual de las nieves y por sus condiciones de humedad crece en ellas variada y abundante vegetación de poca altura, pese a que en la actualidad se encuentra seriamente empobrecida y alterada por el excesivo pastoreo representado principalmente por las "veranadas" y las actividades asociadas a éstas tales como el aprovisionamiento de plantas leñosas aptas para mantener encendidos los fogones de los arrieros. Estos utilizan preferentemente Laretia accaulis, Discaria chacaye (G. Don) Tortosa, Discaria nana (Clos) Benth. \& Hook. F. ex Weberb., Kageneckia angustifolia D. Don u "olivillo", Acaena sp. Mutis ex L. o "clonqui", especie endémica que resiste temperaturas de $-20^{\circ} \mathrm{C}$. Dicha alteración ha facilitado el reemplazo de algunas especies por otras herbáceas introducidas como Erodium cicutarium (L.) L'Hér. ex Aiton, Heliotropium sp. L., Chenopodium album L., Cycloloma atriplicifolium (Spreng.) J. M. Coult., y Poaceae anuales no nativas (Hoffmann et al. 1998). La influencia estacional de la primavera llega a cotas por sobre los $2.000 \mathrm{msm}$ más tarde que en los valles y costa de la región central, debido a que los fríos invernales se prolongan mayor tiempo, incidiendo en las alternativas de desplazamientos humanos hacia y desde los sectores ubicados a mayor altitud y sectores trascordilleranos.

\section{Metodologías Integradas. Estudio Arqueobotánico y Morfológico}

El objetivo general del estudio arqueobotánico fue efectuar un reconocimiento de los recursos vegetales y distintos materiales asociados que han permanecido en los sedimentos del sitio como parte de las actividades de habitación y subsistencia de 


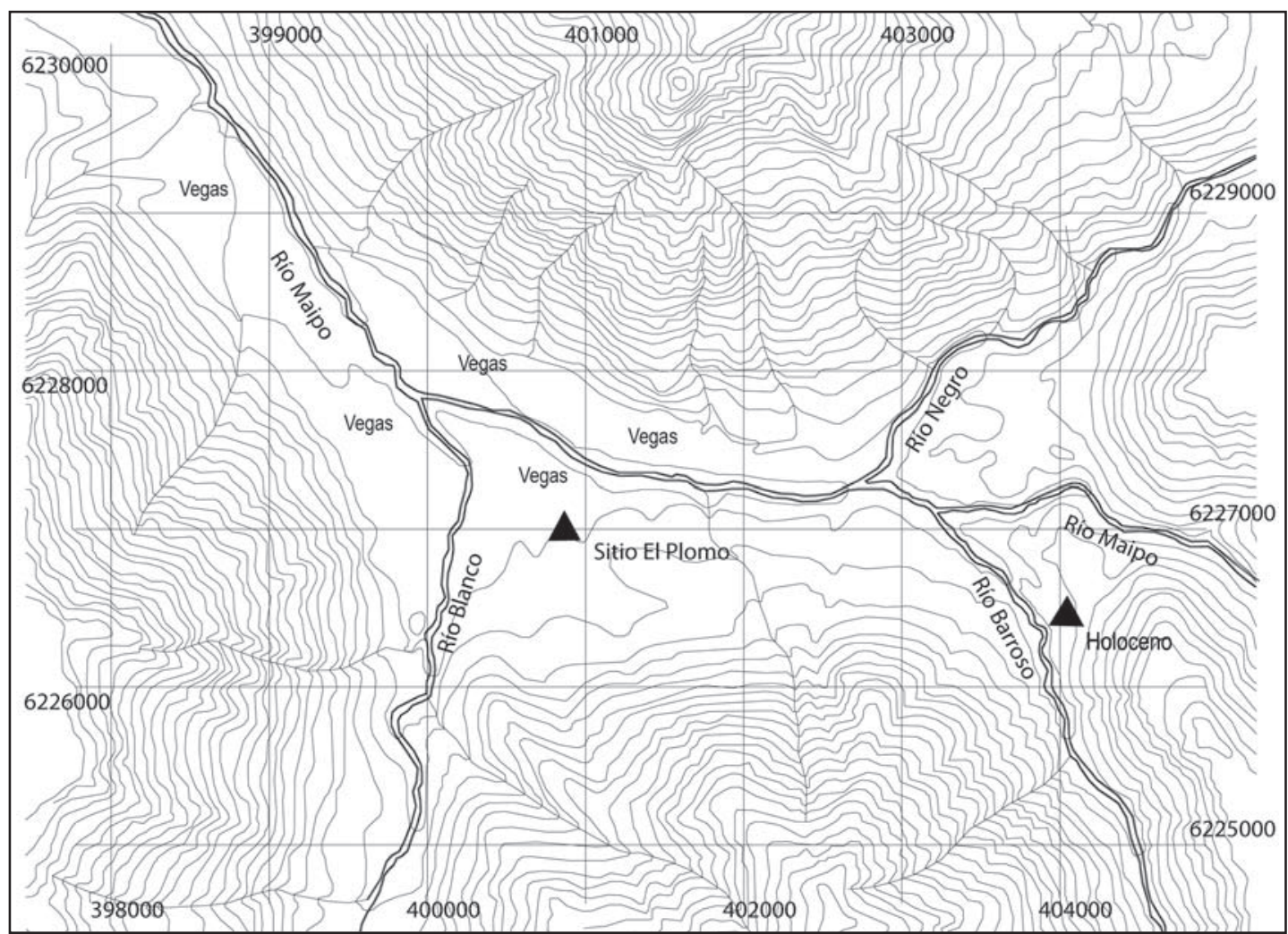

Sistema de Coordenadas UTM PSAM 56 Huso $19 \mathrm{H}$

Figura 1. Mapa de ubicación del sitio El Plomo y sectores con vegas altoandinas.

Map showing the location of the archaeological site of $\mathrm{El}$ Plomo and the highland vegas.

los grupos cazadores recolectores que se instalaron temporalmente en este sector de vegas altoandinas. Era prioritario además corroborar en otros sitios cordilleranos los hallazgos de cultígenos carbonizados (cf. Chenopodium quinoa Willd.) efectuados en el sitio Las Morrenas 1 fechados por AMS en 3.250 a 2.980 años cal. a.p. (Planella et al. 2005).

En el sitio El Plomo (3.460 a 3.340 años cal. a.p.) se da por primera vez en niveles de ocupación del Arcaico IV el encuentro de frutos de Chenopodium sp. (cf. C. quinoa) ${ }^{1}$ conservados sin carbonizar, desecados, lo que permitía efectuar estudios anexos de morfología, taxonomía y, a futuro, de filiación genética. Esta condición es excepcional en la región central de Chile y podría ser explicada por el tipo de depósito anóxico, o fondo de paleovega, de color negro que caracteriza el subsuelo del sitio. Por el tipo de hallazgos, macrorrestos carbonizados y desecados, se detallan en adelante los correspondientes procedimientos metodológicos efectuados. Estos son flotación y análisis de sedimentos y estudios morfológicos de los especímenes desecados.

La flotación de sedimentos y análisis de macrorrestos del sitio El Plomo se realizó con muestras obtenidas en dos unidades de excavación, Cuadrícula 1 y Pozo 8, las que se inscriben dentro del área de 38 x $24 \mathrm{~m}$ en que se concentra la mayor densidad de materiales en el sitio (Figura 2). En la excavación de estas unidades se siguió la estratigrafía natural del sitio y se seleccionaron sectores donde efectuar las columnas de muestras de sedimentos para el estudio arqueobotánico programado. Como actividad anexa, se confeccionó un herbario de referencia de la flora existente en la localidad.

En el procedimiento de flotación (Pearsall 1987) se utilizó una máquina convencional en la que fueron sometidas a flotación 18 muestras de sedimentos, alcanzando un total de 64,2 litros. De cada una de las muestras, antes de ser flotadas, se guardó una reserva de sedimentos de entre 0,100 y 0,200 litros con el fin de efectuar distintos análisis 


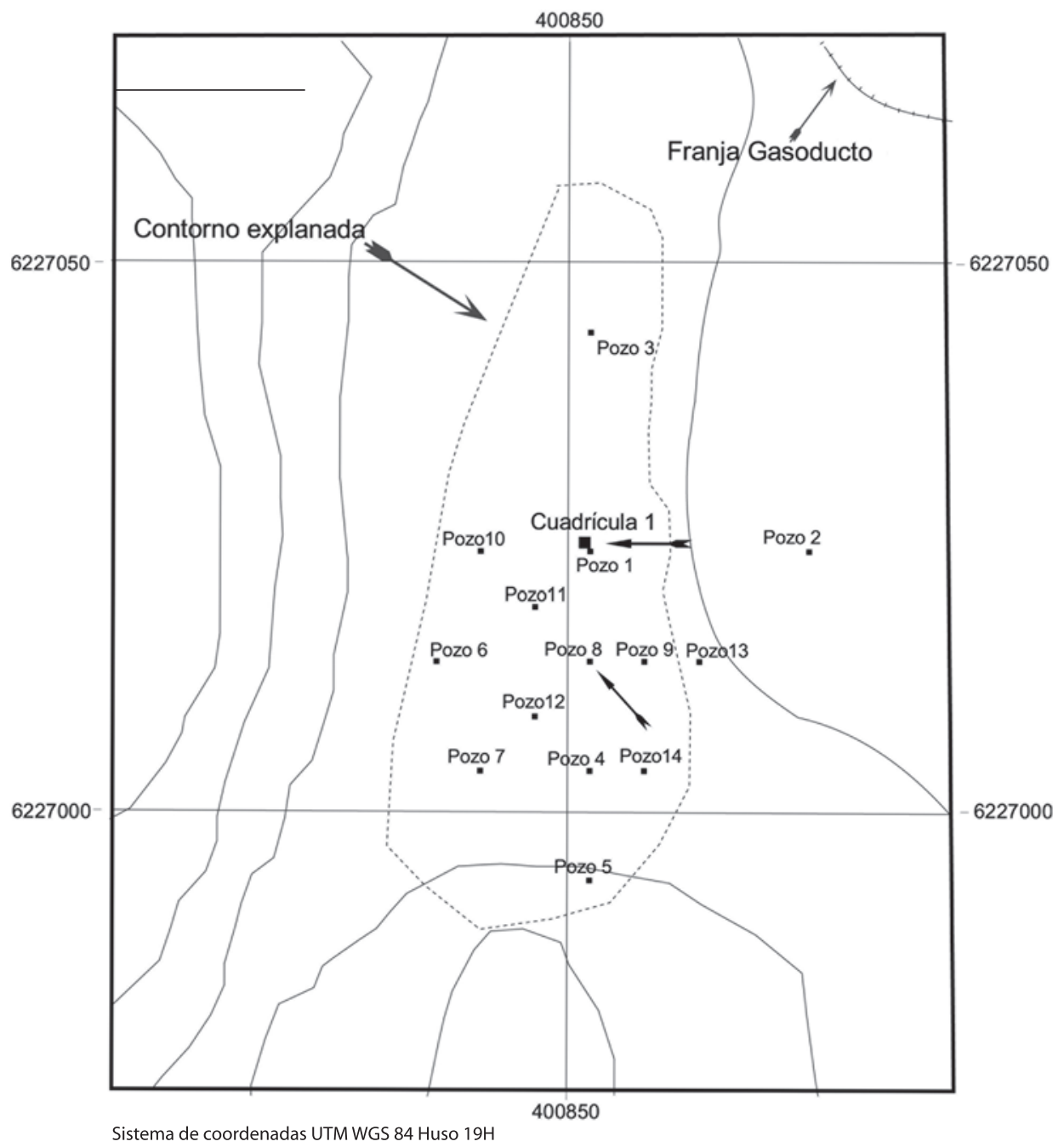

Figura 2. Plano del sitio El Plomo con unidades excavadas. Las flechas indican las unidades muestreadas. Site map of El Plomo showing the locations of excavation units. Arrows indicate sampled pits.

a futuro. Luego se midió en litros cada muestra a flotar, y se registraron las características visualizadas en los sedimentos. Tras dicho procedimiento y una vez separadas las muestras en fracciones livianas (1 a $2 \mathrm{~mm}$ ) y pesadas (mayores a $2 \mathrm{~mm}$ ) se dejaron secar a ambiente natural con sus etiquetas correspondientes, procediendo posteriormente al análisis de macrorrestos utilizando una lupa binocular Nikon SMZ-1B. La presencia cualitativa y cuantitativa de éstos se detalla en Tabla 2.

Por la particularidad de su hallazgo, se separaron los frutos carbonizados $(\mathrm{n}=110)$ y desecados $(\mathrm{n}=99)$ de Chenopodium sp. cf. C. quinoa con el fin de destacar su presencia en las unidades y niveles de depósitos culturales del sitio (Tabla 1) y efectuar estudios comparativos con otros hallazgos arqueológicos de especímenes carbonizados en la costa, valles y cordillera de la zona central (Planella y Tagle 2004; Quiroz y Belmar 2004) y con otros disponibles en estado desecado de sitios de la región trasandina en Los Morrillos de Ansilta, en San Juan (Gambier 1977) y Gruta del Indio en Atuel, Mendoza (Gil 1997-98; Lagiglia 1968). La recuperación excepcional de ejemplares no carbonizados de Chenopodium sp. con el color de superficie inusualmente conservado, y presencia de rasgos morfológicos de intervención antrópica (Figura 3), incentivó el desarrollo de consultas con especialistas 
Tabla 1. Presencia de Chenopodium carbonizados y desecados en distintas unidades y niveles estratigráficos del sitio El Plomo.

Charred and desiccated Chenopodium presence in different units and stratigraphic levels at El Plomo site.

\begin{tabular}{ccc}
\hline & Desecadas & Carbonizadas \\
\hline Cuadrícula 1 & & \\
Nivel 3 A & 3 & 11 \\
Nivel 3 B & 3 & 5 \\
Nivel 2 B & & 6 \\
Nivel 4 A & & 3 \\
Total & $\mathbf{6}$ & $\mathbf{2 5}$ \\
\hline Pozo sondeo 8 & & \\
Nivel 1 & 1 & 2 \\
Nivel 2 a & 42 & \\
Nivel 2 b & 13 & \\
Nivel 2 c & 18 & 51 \\
Nivel 2 e & 19 & 29 \\
Nivel 3 b & & 3 \\
Total & $\mathbf{9 3}$ & $\mathbf{8 5}$ \\
\hline TOTAL & $\mathbf{9 9}$ & $\mathbf{1 1 0}$ \\
\hline
\end{tabular}

de distintos centros de investigación. Como parte fundamental de este estudio se tomaron imágenes de nueve especímenes (frutos) arqueológicos desecados en microscopio electrónico (SEM) en la Universidad de Berkeley, California (Figuras 4a y 4b), y de dos especímenes en la Universidad Católica de Chile, uno de Chenopodium pallidicaule actual y el otro desecado de El Plomo (Figuras 5a y 5b) con el fin de visualizar rasgos micromorfológicos susceptibles de ser comparados con los de Chenopodium cultivados.

Estudios morfológicos realizados en 20 frutos desecados de cf. C. quinoa del sitio El Plomo, luego de ser limpiados con agua y etanol, mostraron mayor similitud con muestras recientes de C. pallidicaule Aellen (cañihua o kañawa) que con muestras de C. quinoa actuales, lo que derivó a análisis de frutos de esa especie. El tamaño de los especímenes de El Plomo ( 0,8 a $1 \mathrm{~mm}$ de diámetro, con una media de $0,84 \mathrm{~mm}$ y margen truncado redondeado) es bastante más pequeño que el de $C$. quinoa actual procedente de Isluga (con un diámetro medio de 2,115 mm, margen truncado), y también menor a la quinoa costera actual de la zona central (diámetro medio de 1,725 $\mathrm{mm}$ y margen truncado). Esto sugería que se trataba de cañihua (diámetro medio de $0,935 \mathrm{~mm}$ ) en vez de quinoa como inicialmente se pensó (Figura 6). En la Universidad de Concepción, y en el Instituto de Ecología y Biodiversidad de la Universidad de Chile, debido a que no hay referencias anteriores de C. pallidicaule arqueológico en la región central de Chile, se realizaron pruebas adicionales hirviendo semillas actuales de cañihua con el fin de extraer la radícula o embrión y compararlas con las de El Plomo que por alguna razón, aún en estudio, no la presentan. En estas condiciones, ambas muestras presentaron similitudes morfológicas especialmente en la forma umbonada de su base y su color, diferenciándose éste del color blanco opaco del perisperma de C. quinoa altiplánica (Alicia Marticorena, comunicación personal 2009) y del blanco traslúcido de la quinoa costera de Chile central (Tagle y Planella 2002). Es difícil hacer un estudio más detallado con las semillas arqueológicas, ya que éstas se encuentran deshidratadas, con pérdida de radícula y de testa, y no se cuenta con otras partes de la planta que permitan un mejor diagnóstico. A su vez, la distribución espacial natural conocida de $C$. pallidicaule no alcanza al territorio central de Chile; está determinada como una especie diploide, a diferencia de C. quinoa, que es tetraploide (Gandarillas 1974).

\section{Resultados}

La investigación arqueológica define el sitio El Plomo como un exponente de ocupaciones semipermanentes (Miranda y Peñaloza 2010) de cazadores recolectores del período Arcaico IV en el ámbito cordillerano, con particulares logros en su sistema de subsistencia que fueron evidentes a través del estudio arqueobotánico. Hasta aproximadamente los 50-60 cm de profundidad, los macrorrestos vegetales son consistentes con el contexto Arcaico IV del alero Las Morrenas 1 (Planella et al. 2005). Por debajo de dicho nivel, el material asignable al Arcaico III acusa diferencias con una muy reducida cantidad de familias y especies botánicas en los registros (Tabla 2), huesos de fauna blanqueados posiblemente por exposición durante un tiempo prolongado y material colorante rojo. En todos los niveles estratigráficos analizados son similares las características del sedimento, fino y de color negro intenso, que ha impregnado todos los materiales, y solo varían por la mayor o menor inclusión de clastos angulosos; la presencia predominante de desechos de obsidiana concuerda con los resultados del análisis del material lítico recuperado en el proceso de excavación (Miranda y Peñaloza 2010). El material óseo está representado principalmente 


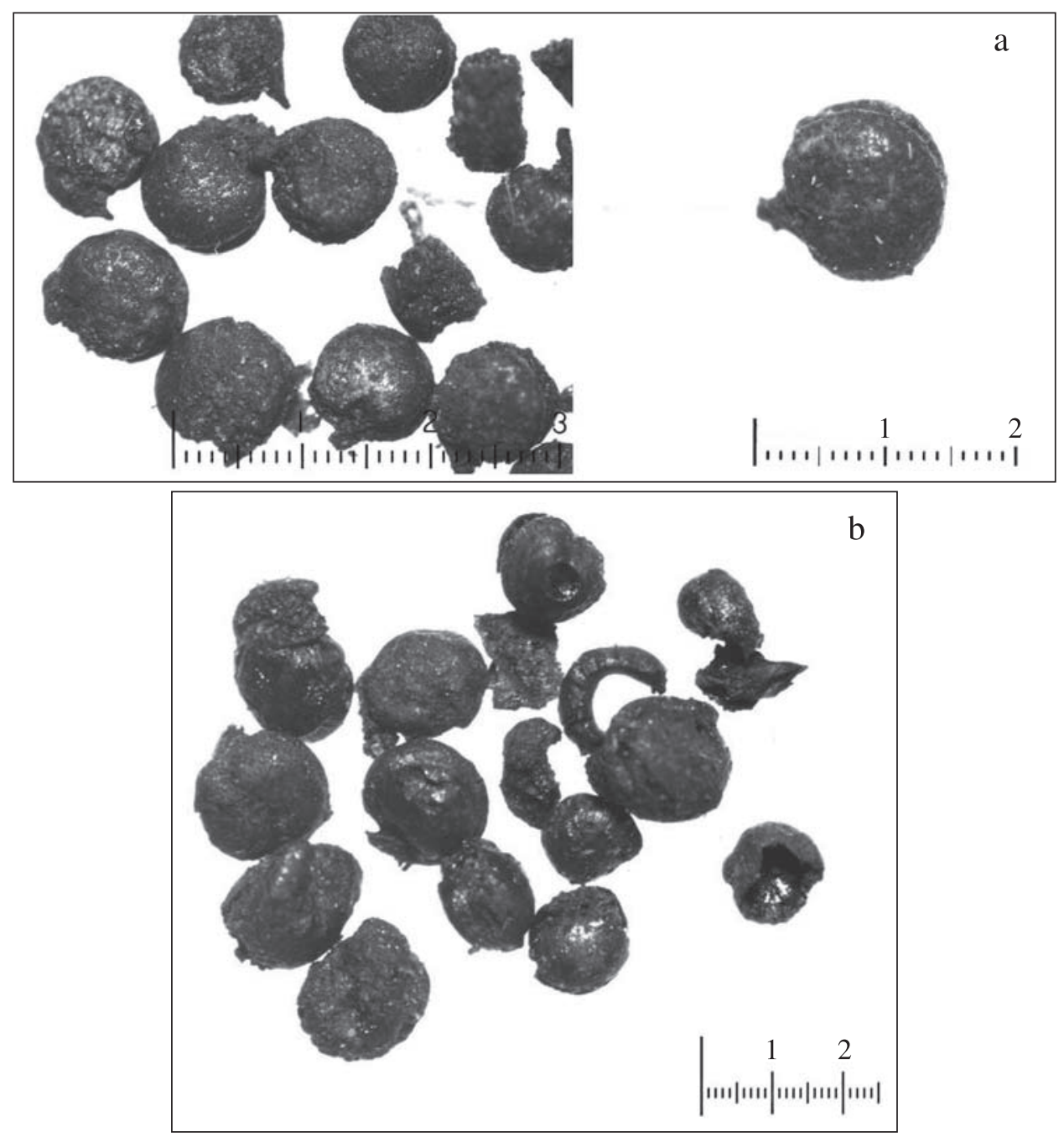

Figura 3. Frutos de Chenopodium cf. C. quinoa en el sitio El Plomo. (a) En estado desecado, (b) carbonizados. Escala en mm. Fruits of Chenopodium $c f$. C. quinoa at El Plomo: (a) desiccated fruits, and (b) charred fruits. Scale in mm.

por fragmentos de huesos largos astillados, algunos aguzados (Lama guanicoe?) en la fracción pesada de la mayoría de las muestras y en particular en los niveles 2 de ambas unidades de excavación, así como dientes de Rodentia sp. en el nivel 3 del Pozo 8.

De los macrorrestos silvestres carbonizados de los depósitos del Arcaico IV (Tabla 2) que sugieren recolección, destaca la presencia de Fabaceae y subfamilia Papilionoideae. Son frecuentes en la precordillera y cordillera hasta los $2.300 \mathrm{msm}$ (Lathyrus sp., L., Astragalus bustillosii Clos, Vicia andina Phil.). Algunas especies de esta familia crecen hasta los $3.300 \mathrm{msm}$ como Adesmia gracilis Meyen ex Vogel o "acerillo" y A. subterranea Clos o “cuerno de cabra". El género Adesmia es exclusivamente sudamericano y en Chile existen 92 especies endémicas (Squeo et al. 1994). La recuperación de frutos (cápsula tricoca) de una Rhamnaceae (Discaria sp.), de conocida eficacia como leña, coincide con lo observado en el alero Las Morrenas 1, ratificando su existencia y utilización en el hábitat cordillerano desde tiempos bastante pretéritos.

Son especialmente interesantes las cariopsis de Poaceae con medidas de 6 a $7 \mathrm{~mm}$ en su eje longitudinal, un atractivo tamaño difícil de pasar desapercibido para los recolectores; y los frutos tanto carbonizados (Figura 3b) como desecados (Figura 3a) de Chenopodium sp. (cf. C. quinoa), los 
Tabla 2. Presencia de macrorrestos vegetales carbonizados y desecados en sitio El Plomo. Charred and desiccated vegetal macro remains at $\mathrm{El}$ Plomo site.

\begin{tabular}{|c|c|c|c|c|c|c|c|c|c|c|c|c|c|c|}
\hline & & 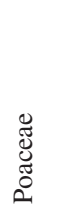 & 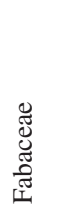 & 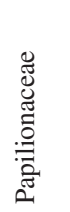 & 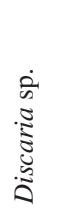 & 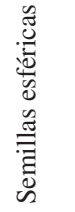 & 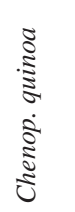 & 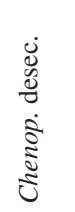 & $\begin{array}{l}\dot{2} \\
\text { के } \\
\stackrel{\Xi}{\Xi} \\
\tilde{\Xi}\end{array}$ & 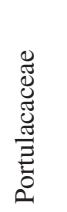 & 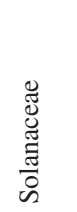 & 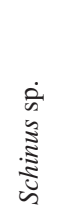 & 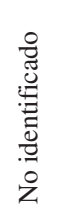 & $\begin{array}{l}0 \\
\stackrel{0}{0} \\
0 \\
0 \\
0 \\
0 \\
0 \\
0 \\
z\end{array}$ \\
\hline \multicolumn{15}{|l|}{ Cuadrícula 1} \\
\hline Nivel 1 & 2 litros & 1 & & & & 3 & & & & & & & & \\
\hline Nivel 2 A & 4,5 litros & & & 4 & 1 & 13 & & & & & & & 2 & \\
\hline Nivel 2 B & 4,5 litros & 78 & & 6 & & 54 & 6 & & & & & & 7 & 8 \\
\hline Nivel 3 A & 3,5 litros & 38 & 3 & & & 187 & 11 & 3 & 3 & & & & 67 & \\
\hline Nivel 3 B & 1,5 litros & 10 & 1 & 10 & & 61 & 5 & 3 & 3 & & 18 & & 3 & 40 \\
\hline Nivel $4 \mathrm{~A}$ & 3 litros & 9 & 19 & & 1 & 87 & 3 & & 9 & & & & 5 & 78 \\
\hline Total & & 136 & 23 & 20 & 2 & 405 & 25 & 6 & 15 & & 18 & & 84 & 126 \\
\hline \multicolumn{15}{|c|}{ Pozo sondeo 8} \\
\hline Nivel $1 \mathrm{SW}$ & 3 litros & 6 & 3 & 3 & & 3 & 2 & 1 & & & & & & \\
\hline Nivel 2c SW & 4 litros & 49 & & & & 75 & 51 & 18 & 5 & & & & 7 & \\
\hline Nivel 2e SW & 4,5 litros & 21 & & 25 & & 150 & 29 & 19 & 11 & 2 & & & & \\
\hline Nivel 2b SW & 3,5 litros & 38 & & 128 & & & & 13 & 10 & & & & & \\
\hline Nivel 2a SW & 3,5 litros & 71 & 9 & 31 & 3 & 87 & & 42 & 48 & & & & 7 & \\
\hline Nivel 3a SW & 4 litros & 7 & & 21 & & 130 & & & & & & 1 & 16 & \\
\hline Nivel 3b SW & 3,5 litros & 9 & & 32 & & 92 & 3 & & 7 & 3 & 1 & & 2 & 5 \\
\hline Nivel 3c SW & 3,5 litros & 2 & & 9 & 1 & 27 & & & & & 1 & & 3 & 6 \\
\hline Nivel 4a SW & 4,3 litros & & & 2 & & & & & 1 & & & & 6 & \\
\hline Nivel 4b SW & 4 litros & 3 & & & & & & & & & & & 1 & 4 \\
\hline Total & & 206 & 12 & 251 & 4 & 564 & 85 & 93 & 82 & 5 & 2 & & 42 & 15 \\
\hline
\end{tabular}

que desaparecen en el registro prácticamente por debajo del nivel $3 \mathrm{~B}$ o nivel 4, en que se manifiestan materiales de una ocupación anterior. El estudio arqueobotánico realizado en siete sitios de cazadores recolectores de fines del Arcaico en la cordillera de la cuenca del río Maipo, hasta ahora ha demostrado que solo en dos de ellos, Las Morrenas 1 y El Plomo, hay evidencias de Chenopodium sp. (cf. C. quinoa). Los otros sitios corresponden a Condominio 1 (3.475 a 3.370 años cal. a.p.), Holoceno (4.850 a 4.440 años cal. a.p.), La Batea 1 (4.835 a 2.760 años cal. a.p.), La Paloma (3.375 a.p.), Las Cortaderas 2 у 3 (4.425 a.p. y 4.405 a.p.).

Los 110 frutos carbonizados de Chenopodium sp. cf. C. quinoa de El Plomo son similares a aquellos recuperados en Las Morrenas 1 tanto en el nivel Arcaico IV como en el Alfarero Temprano. La presencia de 99 frutos desecados en los sedimentos analizados es excepcional en la región. Esta condición de preservación fortuita por las características del sedimento incidió en la obtención de datos morfológicos y puede servir como material para un futuro estudio de su posición filogenética dentro de Chenopodium.

Algunos rasgos diagnósticos de manipulación antrópica de estas Chenopodiaceae son sugeridos por el color blanco-amarillento-castaño del perisperma, el margen truncado-redondeado asignado a C. pallidicaule (Bruno 2006), y la prominencia del "beak" o extremo sobresaliente del embrión en el total de la muestra, rasgo considerado por otros autores para $C$. berlandieri en Norteamérica (Smith y Yarnell 2000) como se aprecia en las Figuras 3a y $5 \mathrm{~b}$. El espesor de la testa ${ }^{2}$ no ha sido determinado en los especímenes de El Plomo por la escasa o nula definición que ésta presenta en las imágenes de SEM (María Bruno, comunicación personal 2010). Interesa comentar que en las investigaciones de Bruno y Whitehead (2003:349-350) en asentamientos del período Formativo de Chiripa, en Bolivia, las semillas de Chenopodium sin presencia de testa son las más abundantes (59\%) en las dos 
fases más antiguas de Chiripa (1.500 a 800 a.C) y que la pérdida de este atributo se debería a perturbaciones pre o postdepositacionales que habrían causado que las delgadas testas se desarticulen (Pilar Babot, comunicación personal 2010), lo que también puede incidir en el reducido tamaño de los especímenes encontrados.

En cuanto a sugerir su adscripción a una especie determinada, es un tema pendiente por las dificultades señaladas. Pese a ello, fueron importantes los estudios morfológicos y comparativos, distanciando estos frutos de El Plomo de los de C. quinoa por la diferencia de sus diámetros medios
(Figura 6), color del perisperma y forma del margen, y aproximándolos tentativamente a $C$. pallidicaule o cañihua por presentar la base umbonada, similitud de su tamaño (0,8 a $1 \mathrm{~mm}$ de diámetro) y del sector perimetral al extraer la radícula en laboratorio. La ausencia de radícula en los especímenes de El Plomo (Figuras 4a y 4b) no se explica fácilmente, ya que los que están carbonizados la presentan o la tienen desprendida (Figura 3b) y podría tratarse de un estado inmaduro del fruto o de problemas tafonómicos pre o postdepositacionales como sucede con la ausencia de testa en especímenes de Chiripa antes mencionados (Bruno 2006). En nuestra experiencia

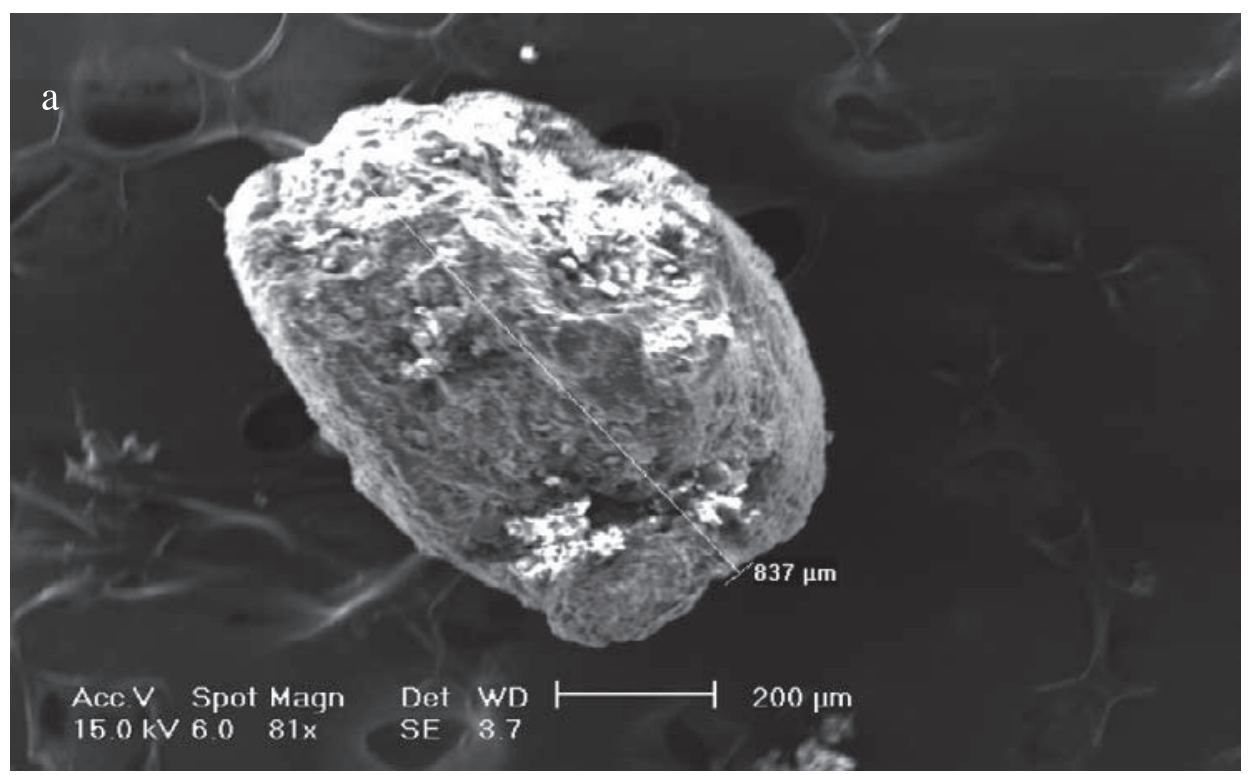

b

Margen con ausencia de

radícula

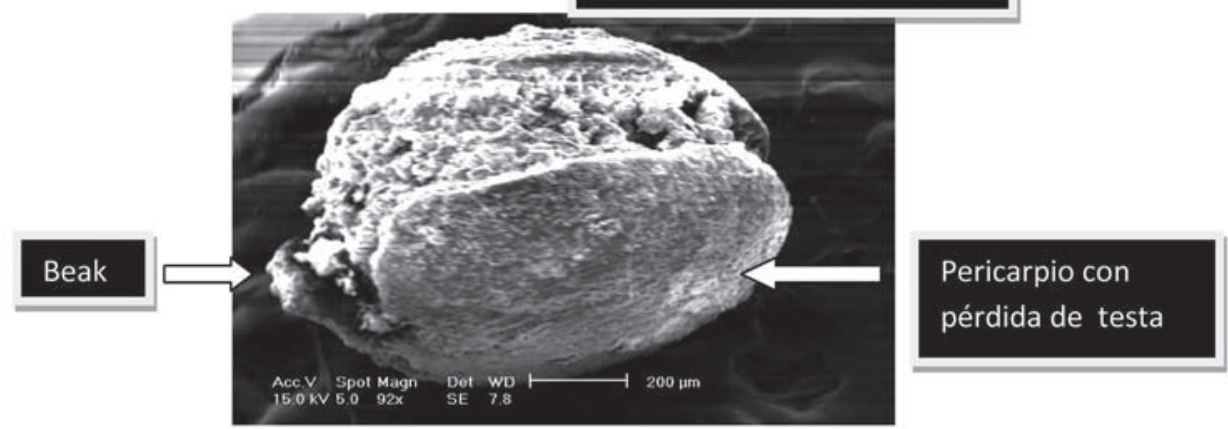

Figura 4. Imágenes de Chenopodium desecados de El Plomo en microscopio de barrido (Universidad de California, Berkeley): (a) medidas de diámetro, y (b) se aprecia el margen o borde truncado-redondeado, ausencia de radícula y la presencia de "beak" pronunciado.

SEM images of the desiccated Chenopodium (University of California, Berkeley) from El Plomo, showing: (a) the diameter, and (b) the truncated-rounded margin, absence of the embryo and a marked "beak". 


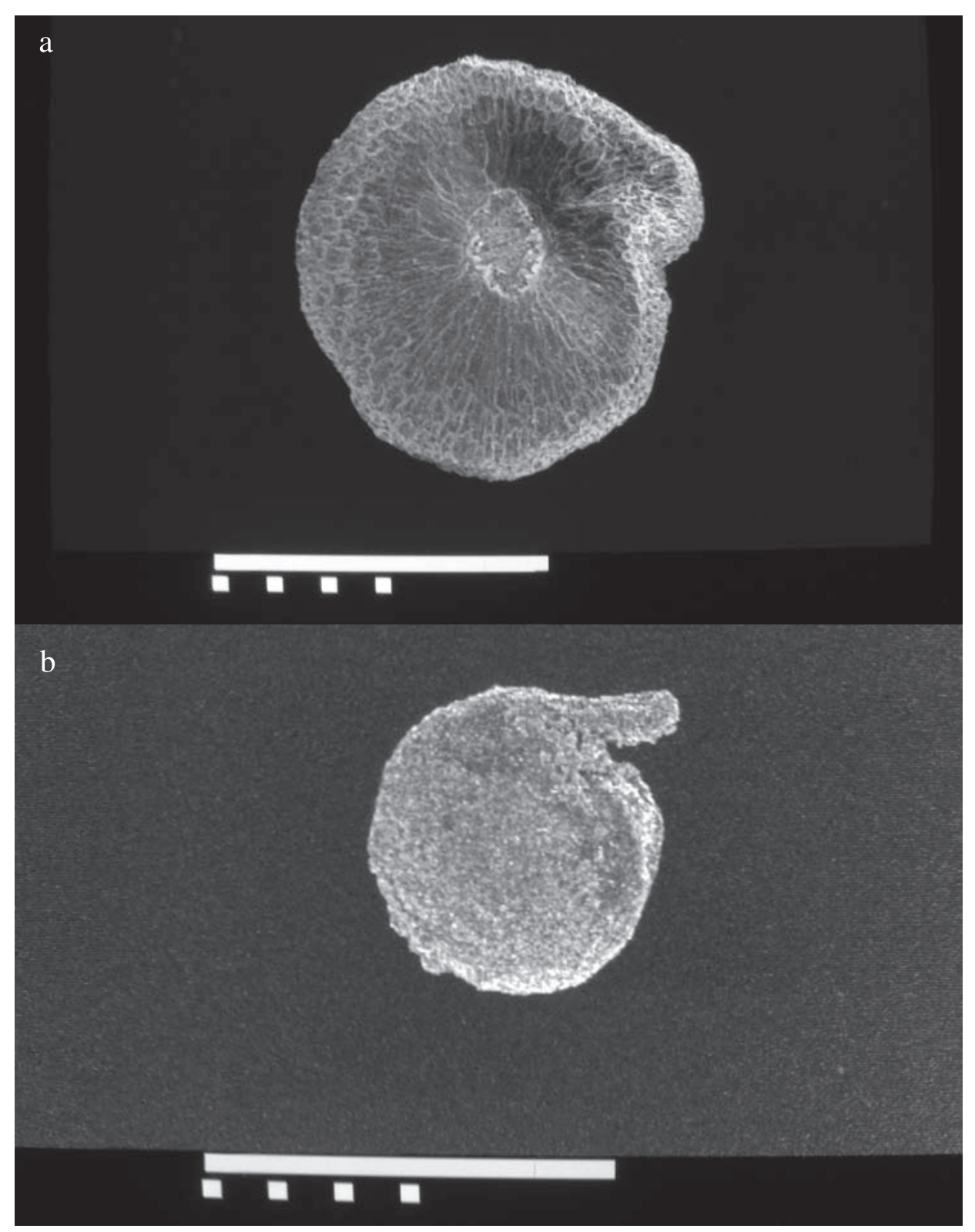

Figura 5. Imágenes en microscopio de barrido (U. Católica de Chile) de Chenopodium pallidicaule: (a) fruto de cañihua o cañawa actual, (b) Chenopodium desecado de sitio El Plomo, con borde truncado-redondeado y "beak" pronunciado.

SEM images of Chenopodium pallidicaule (Universidad Católica de Chile): (a) fruit of the modern cañihua or kañawa, and (b) desiccated Chenopodium from El Plomo with truncated margin and a marked "beak".

de laboratorio, al hervir las semillas actuales de C. pallidicaule se desprendieron las radículas o embrión perimetral y parte de la testa. Este mismo procedimiento, efectuado en $C$. quinoa, no logra reducir el tamaño del fruto a aquel que presentan los mencionados de El Plomo. En la comparación con especímenes arqueológicos de sitios trasandinos, la morfología de aquellos desecados de Los Morrillos de Ansilta sí corresponde a C. quinoa, no obstante en los que provienen de Cueva del Indio en Atuel se aprecian dos tipos de semillas desecadas; unas de color castaño claro y forma típica de quinoa, con margen truncado y embrión perimetral amarillo; las otras son más oscuras, negras brillantes bajo el 


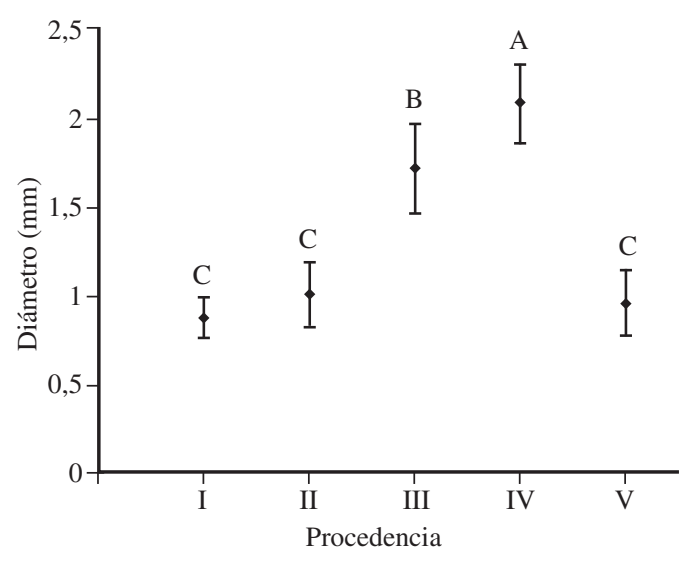

Figura 6. Comparación del diámetro ecuatorial de frutos de Chenopodium sp. de diferentes localidades, que se denominan con números romanos en el eje Y. I: Chenopodium sp. El Plomo, desecadas; II: Chenopodium sp. El Plomo carbonizadas; III: C. quinoa actual costera, zona central de Chile; IV: C. quinoa actual, Isluga; V: C. pallidicaule actual, sur de Perú. Los puntos representan promedios de tamaño en $\mathrm{mm}$, con sus respectivas barras de desviación estándar, de un total de 20 frutos por grupo, fotografiados bajo lupa y medidos en forma digital con el programa ImageJ64 (Abramoff 2004). Letras distintas sobre los promedios representan diferencias significativas entre promedios, según el test de comparaciones de pares de Tukey-Kramer $(\alpha=0,05)$, realizado con el programa estadístico JMP5.1.1 (SAS Institute Inc., Cary, NC, 2004).

Comparison of the equatorial diameter of the fruits of Chenopodium $s p$. taken from different localities, which are labeled in roman numerals along the $Y$ axis. I: desiccated Chenopodium sp. El Plomo; II: charred Chenopodium sp., El Plomo; III: modern C. quinoa, central coastal Chile; IV: modern C. quinoa, Isluga; V: modern C. pallidicaule, southern Peru. Dots represent size averages in $\mathrm{mm}$ with standard deviation lines from a total of 20 fruits per group, photographed under a magnifying glass and measured digitally using the software ImageJ64 (Abramoff 2004). The letters above the averages represent significant differences among the averages according to the Tukey-Kramer $(\alpha=0.05)$ test for pairwise comparisons performed using the statistical software JMP5.1.1 (SAS Institute Inc., Cary, NC, 2004).

pericarpio, con forma algo distinta a las anteriores (Alicia Marticorena, comunicación personal 2009) y similares a Chenopodiaceae silvestres que frecuentemente acompañan a las cultivadas.

\section{Comentarios}

El aporte de nuevas evidencias de cultígenos en un sitio más de cazadores recolectores de finales del Arcaico en la cordillera de Chile central lleva a reforzar los planteamientos surgidos en el estudio del sitio Las Morrenas 1 (Planella et al. 2005). Se confirma, al menos en los restos carbonizados, a Chenopodium sp. cf. C. quinoa como cultígeno que emerge inicialmente en la región central de Chile, hacia el 3.400 a.p., en un sector altoandino con acceso a pasos cordilleranos que comunican con la vertiente oriental. La proximidad morfológica de los frutos desecados con C. pallidicaule sugiere ampliar la orientación de los estudios hasta ahora realizados, revisar las colecciones disponibles y mantener hasta nuevas evidencias su designación como Chenopodium sp. Pese a que estas determinaciones aún no son definitivas, es evidente que algunos de los grupos cazadores amplían su base de subsistencia, sin dejar de ser recolectores, con un aporte de proteínas y aminoácidos de origen vegetal con la ingesta de Chenopodiaceae, que complementan y dan mayor balance a la dieta. $\mathrm{La}$ información isotópica disponible sobre un escaso número de individuos arcaicos $(n=3)$ estudiados de la cordillera de Chile central, dos de ellos con fechas del Arcaico IV (Los Hornos y Alero La Paloma), indica una dieta monoisotópica basada en recursos vegetales $\mathrm{C} 3$, con un valor promedio $\delta 13 \mathrm{Ccol}$ de $-18,6 \%$ y un valor promedio $\delta 13 \mathrm{Cap}$ de $-11 \pm 1,6 \%$ o (Tykot et al. 2009).

En el registro arqueobotánico se destaca la presencia de cariopsis de Poaceae carbonizadas, de un tamaño y abundancia estival atractivos para ser recolectadas (Figura 7) y de frutos de Chenopodiaceae tanto carbonizados como desecados. Ambos son recursos vegetales de importancia en la alimentación humana, como potencial de molienda y para consumo

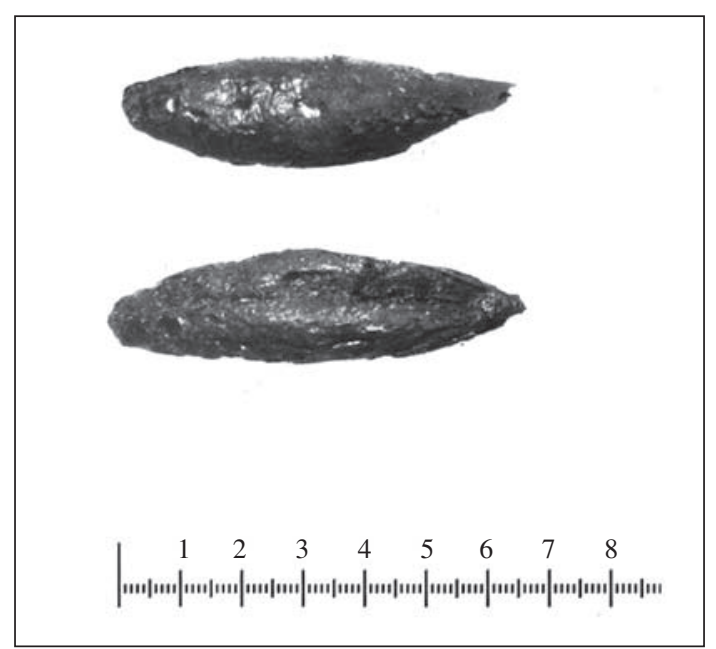

Figura 7. Cariopsis carbonizados de Poaceae de sitio El Plomo. Escala en $\mathrm{cm}$.

Charred Poaceae cariopsis from El Plomo. Scale in cm. 
en condiciones de tostado sobre piedras calientes u otra modalidad en ausencia de alfarería, a la vez que son susceptibles de almacenar y trasportar con facilidad (Planella et al. 2005). Se ha dado escasa atención a las poaceas o gramíneas como recurso alimenticio aprovechado por los grupos cazadores recolectores tardíos, pese a su gran contenido en carbohidratos y a que en el sistema altoandino presentan una gran cobertura espacial en su crecimiento espontáneo. Fructifican en época estival, que es el periodo que facilita el acceso y permanencia en estos sectores cordilleranos. Sus cariopsis carbonizadas en los depósitos de Las Morrenas 1 y El Plomo son notoriamente frecuentes y mantienen, en el primer sitio, una significativa continuidad en los contextos del periodo Alfarero Temprano (Planella et al. 2005). Su entrada a los depósitos arqueológicos, así como la de otros restos botánicos, puede también, junto a distintas causales, ser producto de la utilización de "dung" de camélidos en vez de o como complemento de leña, pero ello no invalida ni es excluyente de lo que se ha planteado. Existen referentes etnográficos y documentales sobre el uso y cultivo de gramíneas nativas del género Bromus L. en temprana época histórica del centro y sur de Chile como el Bromus mango E. Desv. o "magu", Bromus berteroanus Colla o "teca" y Bromus catharticus Vahl o "lanco" (Aldunate 1996; Latcham 1936; Matthei 1986). Sin mayores estudios taxonómicos para estas cariopsis arqueológicas no hay certeza de que junto con cf. C. quinoa integren un conjunto mínimo de cultígenos en algún momento de fines del Arcaico.

Se ha señalado que no todos los sitios Arcaico IV estudiados aportan datos sobre cultígenos iniciales. Esta presencia diferencial amerita ser analizada a futuro desde distintas perspectivas, teniendo en cuenta desde el factor de toma adecuada de muestras de sedimentos en los sitios, la ubicación de éstos con respecto a pasos cordilleranos y fuentes de aprovisionamiento de materias primas, su carácter como campamentos, aleros rocosos o sitios abiertos, la permanencia de las estadías, la mayor o menor continuidad en el registro de actividades preferenciales (caza, recolección, innovaciones), datos empíricos sobre contactos con otros grupos, el radio de movilidad de estas sociedades.

Como un ejemplo de lo anterior, en ocupaciones cercanas entre sí, hay diferencias entre El Plomo y el sitio Holoceno (Figura 1) desde la perspectiva del estudio realizado. Ambos son sitios abiertos, con fechas que en algún momento coinciden, predominancia del uso de obsidiana como materia prima lítica (Miranda y Peñaloza 2010), pero las ocupaciones están instaladas en diferente tipo de sustrato sedimentario, en un ambiente de vegas el sitio El Plomo con sedimentos de color muy negro que abarcan todo el espacio y niveles del asentamiento, y Holoceno en una hondonada protegida, con sedimentos de color café claro excepto en aquellos sectores en que hay restos de fogones. Se dan notorias diferencias entre ambos sitios en el contenido de macrorrestos vegetales, como lo es la mínima densidad registrada en Holoceno con 21 macrorrestos en 19,75 litros mientras que en la Cuadrícula 1 de El Plomo hay 860 en 19 litros. Una interrogante dice relación con la ausencia de dos de aquellos mayormente representados en El Plomo, tales como Poaceae y Chenopodiaceae cf. C. quinoa tanto en estado carbonizado como desecado. Como se aprecia en la Tabla 2, de 342 restos de Poaceae, principalmente cariopsis, 136 fueron recuperadas en 19 litros, de sedimentos solo de la Cuadrícula 1, volumen similar al total flotado del sitio Holoceno, donde solo hay evidencia de un fragmento. En éste, están ausentes además los frutos de Rhamnaceae, que son frecuentes en fogatas y fogones en la cordillera. Pese a que es un factor a considerar, la influencia de los vientos cordilleranos en la dispersión del material superficial en sitio Holoceno no parece ser la causal más aceptable de las divergencias anotadas ya que el asentamiento de El Plomo ha estado largamente expuesto en el tiempo a similares condiciones. En cuanto al modo de ocupación, las evidencias arqueológicas y arqueobotánicas parecieran indicar que Holoceno, así como varios de los otros sitios estudiados, tuvo carácter de campamento circunstancial de tareas, con estadías cortas o de paso, lo cual diferiría de la ocupación que se ha registrado en El Plomo que corresponde más bien a un campamento semipermanente o campamento residencial estival (Miranda y Peñaloza 2010).

De este modo queda por resolver algunos de estos aspectos que inciden para alcanzar una mejor interpretación desde la arqueobotánica; a la vez que para ello también es fundamental afinar las cronologías, lo que permitiría evaluar diacronías y contemporaneidades o convergencias en la utilización de distintas especies de la flora altoandina y en la incorporación de cultígenos en el sistema social y de subsistencia de los cazadores recolectores que concurrían a estos sectores de Alto Maipo. 
En la Tabla 2 se aprecian otros recursos de flora nativa, posibles productos de recolección. Los frutos de Fabaceae y subfamilia Papilionoideae por lo general son legumbres que contienen semillas pequeñas en su interior y que potencialmente son recursos forrajeros atractivos para el ramoneo animal, pero que no han sido documentados como alimento humano, por lo que extraña la cantidad de estas semillas, siempre carbonizadas, en los niveles analizados. La gran cantidad de pequeñas semillas $(0,3-0,9 \mathrm{~mm})$ en los sedimentos no han sido identificadas en este estudio, si bien la flora altoandina integra a numerosas herbáceas que en sus frutos contienen semillas esféricas muy pequeñas (Hoffmann et al. 1998). Su tamaño es tan mínimo que sugiere desestimarlas como alimento. Se requiere un mayor acercamiento a conocer las propiedades de muchas semillas propicias para molienda y así descartar posibles componentes tóxicos como se ha descrito para Astragalus sp. L. (Matthei 1995; Planella y McRostie 2008).

\section{Conclusiones}

En el sitio El Plomo se confirma nuevamente la presencia de cultígenos iniciales en un momento del Arcaico IV, probablemente entre 3.460 a 3.340 años cal. a.p. Este hallazgo significó un desafío mayor en relación a la presencia de Chenopodiaceae con rasgos de intervención antrópica en sitios de cazadores recolectores, ya que es la primera oportunidad en que sus frutos fueron recuperados tanto en estado carbonizado como en estado desecado, con cifras muy similares entre sí en un mismo sitio, mostrando en esa última condición y de manera excepcional en la región características de color y morfología que fueron susceptibles de ser analizadas y comparadas. Esta investigación deja abierta una línea de discusión que no se había planteado con anterioridad, al recuperar especímenes que derivan la atención hacia la posibilidad de presencia de Chenopodium pallidicaule o de alguna variedad temprana de quinoa en la alta cordillera andina de Chile central, lo que estimula efectuar una revisión de las colecciones arqueológicas y herbarios de Chenopodium disponibles en la región.

En ausencia hasta la fecha de evidencias contemporáneas similares en sitios del valle central y precordillera, el sector de Alto Maipo se propone como un umbral ecológico cultural en que grupos cazadores recolectores del período Arcaico IV incorporaron una importante innovación en su sistema básico de subsistencia. A la luz del estudio arqueobotánico realizado, no todos los contextos de cazadores de fines del Arcaico representan este conocimiento y será interesante pesquisar las razones de esta situación diferencial.

La emergencia de cultígenos en estas sociedades puede ser considerada dentro de un nivel económico incipiente de incorporación o posible manipulación inicial de alimentos; significa una importante diversificación de las actividades de subsistencia que pudo haber afectado su sistema social, ciclos de movilidad y el modo de ocupación de sitios. Gravitante en este sentido es la mayor proximidad de los yacimientos mencionados al acceso a pasos cordilleranos como el de Maipo, que facilitan el transitar hacia y desde la vertiente oriental en época estival y el contacto con grupos con probables experiencias previas en el manejo de este tipo de cultígenos. La existencia de vegas y lagunas altoandinas representa un bien ecológico que debió facilitar las estadías, actividades y apropiación de variados recursos de alimentación en las oportunidades de ocupación de los sitios, aunque no sustentan por sí solas la posibilidad de actividades de siembras locales. Se conoce que en los Andes y altiplano de Perú y Bolivia C. quinoa y $C$. pallidicaule se cultivan desde tiempos prehispánicos, caracterizándose $C$. pallidicaule por su mayor tolerancia a grandes alturas y resistencia en condiciones de clima de hasta $-10^{\circ}$ de temperatura. En Alto Maipo no hay por ahora datos suficientes para fundamentar esta posibilidad.

Es una tarea a futuro efectuar análisis de ADN con las muestras desecadas, con el fin de comparar ambas especies, lograr determinar las relaciones filogenéticas existentes entre las Chenopodiaceae de los sitios arqueológicos mencionados, y con la quinoa o quinwa, subespecie de nivel de mar (Wilson 1988) que aún se cultiva en las regiones VI y VII de la zona central de Chile; esta presenta perisperma traslúcido e inflorescencia glomerulada, ambos rasgos considerados arcaicos (Tagle y Planella 2002). Estos análisis servirían a su vez para complementar los estudios previos documentados en la literatura (Mason et al. 2005; Maughan et al. 2006; Ruas et al. 1999).

Agradecimientos: Este artículo es producto del Proyecto Fondecyt $N^{\circ} 1060228$ Cazadores recolectores de Chile central: antes y después de la producción de alimentos y de la alfarería. 
Agradecemos a Catalina T. Michieli y Rodolfo Gil, quienes proporcionaron semillas de Chenopodiaceae desecadas de los sitios arqueológicos Los Morrillos de Ansilta y Cueva del Indio en Atuel. Comprometen especialmente nuestro reconocimiento Christine Hastorf y BrieAnna Langlie de la Universidad de California, Berkeley, María C. Bruno y Pilar Babot por sus comentarios y respuestas a diversas consultas. A Alicia
Marticorena, especialista en Chenopodiaceae y curadora del Herbario del Departamento de Botánica de la Universidad de Concepción, por el análisis morfológico de los especímenes desecados y actuales. A Alejandro Munizaga y Ximena Verges de la Universidad Católica de Chile, por facilitar la toma de imágenes en microscopio de barrido y lupa binocular. Y a los evaluadores que, derivando sus tiempos, revisaron este artículo.

\section{Referencias Citadas}

Abramoff, M.D., P.J. Magelhaes y S.J. Ram

2004 Image processing with ImageJ64. Biophotonics International 11:36-42.

Aldunate, $\mathrm{C}$.

1996 Mapuche: Gente de la tierra. Etnografía. Serie Culturas de Chile: 111-134. J. Hidalgo, V. Schiappacasse, H. Niemeyer, C. Aldunate, P. Mege, Editores.

Bruno, M.C.

2006 A morphological approach to documenting the domestication of Chenopodium in the Andes. En Documenting Domestication. New Genetic and Archaeological Paradigms, editado por M. Zeder, D. Bradley, E. Emshwiller y B.D. Smith, pp. 32-45. University of California Press, California.

Bruno, M.C. y W.T. Whitehead

2003 Chenopodium cultivation and Formative Period. Agriculture at Chiripa, Bolivia. Latin American Antiquity 14:339-355.

Cornejo, L., M. Saavedra y H. Vera

1998 Periodificación del Arcaico en Chile Central. Una propuesta. Boletín de la Sociedad Chilena de Arqueología 25.

Cornejo, L. y L. Sanhueza

2003 Coexistencia de cazadores recolectores y horticultores tempranos en la cordillera andina de Chile central. Latin American Antiquity 14:389-407.

Gajardo, R

1994 La Vegetación Natural de Chile. Clasificación y Distribución Geográfica. Editorial Universitaria, Santiago.

Gambier, M.

1977 La Cultura de Ansilta. Instituto de Investigaciones Arqueológicas y Museo. Facultad de Filosofía, Humanidades y Artes, Universidad Nacional de San Juan, San Juan.

Gandarillas, $\mathrm{H}$.

1974 Genética y origen de la quinua. Instituto Nacional del Trigo. Boletín informativo $\mathrm{N}^{\circ}$ 9. La Paz.

Gil, A.

1997-98 Cultígenos prehispánicos en el sur de Mendoza. Discusión en torno al límite meridional de la agricultura andina. Relaciones de la Sociedad Argentina de Antropología XXII-XXIII: 295-318.

Hastorf, C.A.

1999 Cultural implications of crop introduction in Andean Prehistory. En The Prehistory of Food: Appetites for Change, editado por C. Gosden y J.G. Hather, pp. 35-58. Routledge, New York.

Hoffmann, A., M. Kalin, F. Liberona, M. Muñoz y J. Watson 1998 Plantas Altoandinas en la Flora Silvestre de Chile. Ediciones Fundación Claudio Gay, Santiago.
Lavallèe, D.

2000 Les premiers producteurs de l'Amérique du Sud. En Premiers Paysans du Monde, editado por J. Guilaine, pp. 191-211. Editions Errance, París.

Lagiglia, $\mathrm{H}$.

1968 Secuencias culturales del centro-oeste Argentino: valles del Atuel y Diamante. Revista Científica de Investigaciones 1(4):159-174. San Rafael, Mendoza.

Latcham, R.

1936 La Agricultura Precolombina en Chile y los Países Vecinos. Ediciones de la Universidad de Chile, Santiago.

Lema, V.S.

2009 Domesticación Vegetal y Grados de Dependencia Ser humano-Planta en el Desarrollo Cultural Prehispánico del Noroeste Argentino. Tesis para optar al grado de Doctora en Ciencias Naturales. Universidad Nacional de La Plata, La Plata.

Mason, S.L., M.R. Stevens, E.N. Jellen, A. Bonifacio, D.J. Fairbanks, C.E. Coleman, R.R. McCarty, A.G. Rasmussen y P.J. Maughan

2005 Development and use of microsatellite markers for germplasm characterization in quinoa (Chenopodium quinoa Willd.). Crop Science 45:1618-1630.

Mathei, O.

1986 El género Bromus L. (Poaceae) en Chile. Gayana Botánica 43:47-110.

1995 Manual de las Malezas que Crecen en Chile. Alfabeta Impresores, Santiago.

Maughan, P.J., B.A. Kolano, J. Maluszynska, N.D. Coles A. Bonifacio, J. Rojas, C.E. Coleman, M.R. Stevens, D.J. Fairbanks, S.E. Parkinson y E.N. Jellen

2006 Molecular and cytological characterization of ribosomal RNA genes in Chenopodium quinoa and Chenopodium berlandieri. Genome 49:825-839.

Miranda, C. y M.A. Peñaloza

2010 Uso diferencial de materias primas líticas por localidad geográfica entre cazadores recolectores del curso superior del río Maipo y sus afluentes. Manuscrito en posesión de los autores.

Pearsall, D.M.

1987 Paleoethnobotany. A handbook of Procedures. Academic Press, New York y London.

1989 Adaptation of prehistoric hunter-gatheres to the high Andes: the changing role of plant resources. En Foraging and Farming. The Evolution of Plant Exploitation, editado por D.R. Harris y G.C. Hillman, pp. 318-332. Institute of Archaeology, University College, London. 
1992 The origins of plant cultivation in South America. En The Origin of Agriculture. An International Perspective, editado por C. Cowan y P. Watson, pp. 173-205. Smithsonian Institution Press, Washington, D.C.

Planella, M.T., L. Cornejo y B. Tagle

2005 Alero Las Morrenas 1: evidencias de cultígenos entre cazadores recolectores de finales del período Arcaico en Chile Central. Chungara Revista de Antropología Chilena 37:59-74.

Planella M.T. y B. Tagle

2004 Inicios de presencia de cultígenos en la Zona Central de Chile, períodos Arcaico y Agroalfarero Temprano. Chungara Revista de Antropología Chilena 36 número especial, Tomo II, pp. 387-400.

Planella, M.T. y V. McRostie

2008 Manejo de la información arqueobotánica y desafíos teóricos: una mirada propositiva desde el sitio Paleoindio Santa Julia, Los Vilos ( $\left.31^{\circ} 29^{\prime}\right)$ Chile. En Arqueobotánica y Teoría Arqueológica. Discusiones desde Suramérica, compilado por S. Archila, M. Giovannettii y V. Lema, pp. 231-249. Ed. Uniandes-Ceso, Departamento de Antropología, Bogotá.

Quiroz, L. y C. Belmar

2004 Estrategias de explotación de recursos vegetales: evidencia arqueobotánica de tres sitios de la región central de Chile: Radio Estación Naval, El Cebollar y Lonquén (E 80-4). Chungara Revista de Antropología Chilena 36 número especial Tomo II, pp. 1109-1119.
Ruas, P.M., A. Bonifacio, C.F. Ruas, D.J. Fairbanks y W.R. Andersen

1999 Genetic relationship among 19 accessions of six species of Chenopodium L., by random amplifies polymorphic DNA fragments (RAPD). Euphytica 105:25-32.

Sanhueza, L. y F. Falabella

1999-2000 Las comunidades alfareras iniciales en Chile central. Revista Chilena de Antropología 15:29-47.

Smith, B.D. y R.A. Yarnell

2009 Initial formation of an indigenous crop complex in eastern North America at 3800 BP. www.pnas.org/agl/ dol/10.1073/pnas090181846106 (enero 2010).

Squeo, F., R. Osorio y G. Arancio

1994 Flora de la Cordillera de Coquimbo: Cordillera de Doña Ana. Ediciones Universidad de La Serena, La Serena.

Tagle, B. y M.T. Planella

2002 La Quinoa en la Zona Central de Chile. Supervivencia de una Tradición Prehispana. Editorial IKU, Santiago.

Tykot, R.H., F. Falabella, M.T. Planella, E. Aspillaga, L. Sanhueza y C. Becker

2009 Stable isotopes and archaeology in Central Chile: Methodological insights and interpretative problems for dietary reconstruction. International Journal of Osteoarchaeology 19:156-170.

Wilson, H.D.

1988 Quinua biosystematics I. Domesticated populations. Economic Botany 42:461-477.

Zeder, M.A., E. Emshwiller, B.D. Smith y D.G. Bradley

2006 Documenting domestication: the intersection of genetics and archaeology. ELSEVIER. Trends in Genetics Vol. 22 $\mathrm{N}^{\mathrm{o}}$ 3. http://www.sciencedirect.com (febrero 2010).

\section{Notas}

1 De manera tentativa hemos denominado a las Chenopodiaceae del sitio como cf. Chenopodium quinoa en espera de una determinación definitiva y de una aproximación a la etapa de manipulación antrópica en que se encuentran.
2 Se denomina testa a la membrana que envuelve el pericarpio y que controla la dormancia de la semilla. Es delgada, menos de $20 \mu \mathrm{m}$ en las semillas de Chenopodium domesticados, y de mayor espesor en las silvestres (Bruno 2006). 